\title{
Cytolytic activity of mitogen activated old and young mouse spleen cells against tumor target cells expressing high or low levels of Fas antigen
}

\author{
Rajiv K. Saxena ${ }^{1,2,3}$ and William H. Adler ${ }^{2}$ \\ ${ }^{1}$ School of Life Sciences, Jawaharlal Nehru University, \\ New Delhi, India \\ ${ }^{2}$ Clinical Immunology Section, NIA National Institutes \\ of Health Baltimore, MD, U.S.A. \\ ${ }^{3}$ Corresponding author: Tel, 91-11-6109779, 6107676 \\ ext 2525(0) 6801843(R); Fax, 91-11-6187338; \\ E-mail, rajivksaxena@ hotmail.com
}

Accepted 30 June 1999

Abbreviations: CM, complete culture medium; FasL Fas ligand

\begin{abstract}
Sensitivity of Fas expressing tumor cells (high levels in Hut78 \& Jurkat; low levels in P815) toward the cytotoxic Con-A $(5 \mu \mathrm{g} / \mathrm{ml})$ activated spleen cells from young (12 to 16 week old males) and old (2 year old males) mice were studied. The spleen cells from young mice activated for a day showed high levels of cytotoxic activity against Hut78 and Jurkat cell lines but not against P815 cells. The cytotoxic activity against P815 cells were detected in the spleen cells from old but not young mice following a longer period of Con-A activation (three days). Comparable levels of cytotoxic activity against Hut78 and Jurkat cells were observed in the spleen cells from both young and old mice following three days of activation. Treatment of Hut78 cells with anti-Fas antibody affected the tumor cells become resistant against the cytotoxic activity of the spleen cells from young mice in a dose dependent manner however $\mathbf{P} 815$ cells were not affect by the anti-Fas antibody treatment. These results show that there are differences in the sensitivity of target tumor cells toward Con-A induced cytotoxic spleen cells from young and old mouse. Mitogen-induced cytotoxic lymphocytes from young mouse spleen appear to kill targets through mechanisms involving Fas antigen, specially, in early stage (1 day) of activation. Old mouse spleen cells generated high levels of cytotoxic cells in later phase (3 days), which appear to kill through Fas-unrelated mechanisms.
\end{abstract}

Keywords: cytotoxic cells, mitogen, Fas, Fas ligand, aging

\section{Introduction}

Many parameters of T-cell activity decline with age. These include T-cell proliferation in response to stimulation through $\mathrm{T}$ cell receptor and co-stimulators (Engwerda et al., 1994; Lerner et al., 1988; Song et al., 1993), production and response to growth promoting cytokines (Ernst et al., 1993; Nagelkerken et al., 1991; Saxena et al., 1988) and generation of cytotoxic T-cells (Hirano and Nordin, 1976; Powers and Belshe, 1993; Mbawuike et al., 1997). We have previously characterized mitogen induced cytotoxic spleen cells from young and old mice and reported differences in their cytolytic activities (Saxena et al., 1981, 1988a). While most T-cell functional activity appears to decline with age, we found that mitogen (Con-A) stimulated spleen cells from old mice compared to young mice, generated markedly higher levels of cytotoxic activity against several tumor cell lines like YAC, P815 and EL4 (Saxena et al., 1988a). Over stimulation of old mouse cytotoxic cells appeared to be due to loss of a feedback regulatory loop involving gamma interferon (Saxena et al., 1988a). It is now believed that cytotoxic lymphocytes can kill targets essentially through two distinct mechanisms (Berke 1997; Nagata and Goldstein 1995). One of these involves the exocytosis of cytolytic granules from the triggered cytotoxic cell, and the other requires the interaction of Fas antigen on target cells with Fas ligand (FasL) on the effector cytotoxic cell. In the present study, we have re-investigated the issue of mitogen induced cytotoxic cells in old and young mouse spleen cells, in order to assess whether the differences in the cytotoxic cell response obtained in the two cases may arise due to differential activation of effector cells resulting in different killing mechanisms. For this purpose, cytotoxic activity of lectin activated spleen cells from young and old mouse spleen cells was studied by using targets which express high or low levels of Fas. The P815 cell line expresses low levels of Fas antigen and is not susceptible to lysis through Fas-FasL mechanism (Tsutsui 1996), whereas the Jurkat and Hut78 cell lines express high levels of Fas antigen and are susceptible to FasL mediated lysis (Alderson et al., 1994; Wong and Goeddel, 1994). Results of our study suggest that the cytotoxic cells generated in young mouse spleen cells activated with Con-A are efficient effectors against Fas 
expressing cell lines, whereas effector cells generated in old mouse spleen cells may kill targets through fas unrelated mechanisms.

\section{Materials and Methods}

\section{Reagents}

Hamster anti-mouse Fas monoclonal antibody preparations and mouse anti-human Fas monoclonal antibody preparations, both with or without FITC coupling, were purchased from Pharmingen, CA. Radioactive Chromium-51 for chromium release assay of cytotoxicity, was obtained from Amersham or from BARC, Mumbai.

\section{Effector and Target cells}

Spleen effector cells used in this study were derived from young or old $\mathrm{C} 57 \mathrm{BI} / 6$ mice. Young male C57BI/6 mice (12 to 16 weeks) were obtained from Jackson Laboratories. Old male C57BI/6 mice (age 24 to 26 months) were from the aging mouse colonies maintained at the National Institute on Aging, NIH, Baltimore, MD. Spleen cell suspensions were prepared by teasing the spleens in cold complete culture medium (CM, RPMI 1640 medium supplemented with Gentamicin (50 $\mu \mathrm{g} / \mathrm{ml})$, 2mercaptoethenol $\left(2 \times 10^{-5} \mathrm{M}\right)$ and $10 \%$ fetal calf serum). Spleen cells $\left(5 \times 10^{6} / \mathrm{ml}\right.$ in CM) were activated by culturing for one or three days with $5 \mu \mathrm{g} / \mathrm{ml}$ ConcanavalinA. At the end of the activation period, spleen cells were washed three times with fresh cold $\mathrm{CM}$ and viable cells counted using Trypan blue dye. Human $\mathrm{T}$ cell lines Hut78 and Jurkat and the mouse mastocytoma line P815 were from American Type Cell Culture (ATCC), Bethesda, MD, and were maintained by serial passages in complete medium.

\section{Flowcytometry}

Tumor cells $\left(5 \times 10^{5}\right)$ were suspended in $0.1 \mathrm{ml} \mathrm{CM}$ containing $1 \mathrm{mg} / \mathrm{ml}$ hamster immunoglobulins (for staining with hamster anti-mouse Fas mab-FITC), or $1 \mathrm{mg} / \mathrm{ml}$ of mouse immunoglobulins (for staining with mouse antihuman Fas-FITC mab), and incubated with $2 \mu \mathrm{g}$ of antiFas antibodies-FITC for 20 minutes at $4 \mathrm{C}$, followed by three washings with cold CM. Stained cells were fixed in $0.1 \mathrm{ml} 2 \%$ paraformaldehyde and analyzed on a Becton Dickinson Facstar flowcytometer.

\section{Cytotoxicity assays}

Labeling of target cells with Chromium-51 and the procedure for the four hour assay of cytotoxicity has been described else where (Saxena et al., 1988b). For studying the effect of anti-Fas antibody on the susceptibility of target lysis, Chromium labeled target cells $\left(5 \times 10^{3}\right.$ target cells in $0.05 \mathrm{ml} /$ assay well) were incubated with desired concentration of the anti-Fas monoclonal anti- bodies for $30 \mathrm{~min}$ at $4 \mathrm{C}$. Effector cells $\left(4 \times 10^{5}\right.$ cells in $0.05 \mathrm{ml} /$ assay well) were then added and plates incubated for a four hour chromium release assay of cytotoxicity.

\section{Results}

\section{Levels of Fas expression on Hut78, Jurkat and P815 tumor cell lines}

Fas-FasL interaction has been recognized as an important killing signal for Fas expressing tumor target cells. Since our aim was to examine the susceptibility of high and low Fas expressing target cells to mitogen activated young and old mouse spleen cells, we selected some tumor cells expressing high or low levels of Fas. Results in Figure 1 indicate that Jurkat and Hut78 cell lines
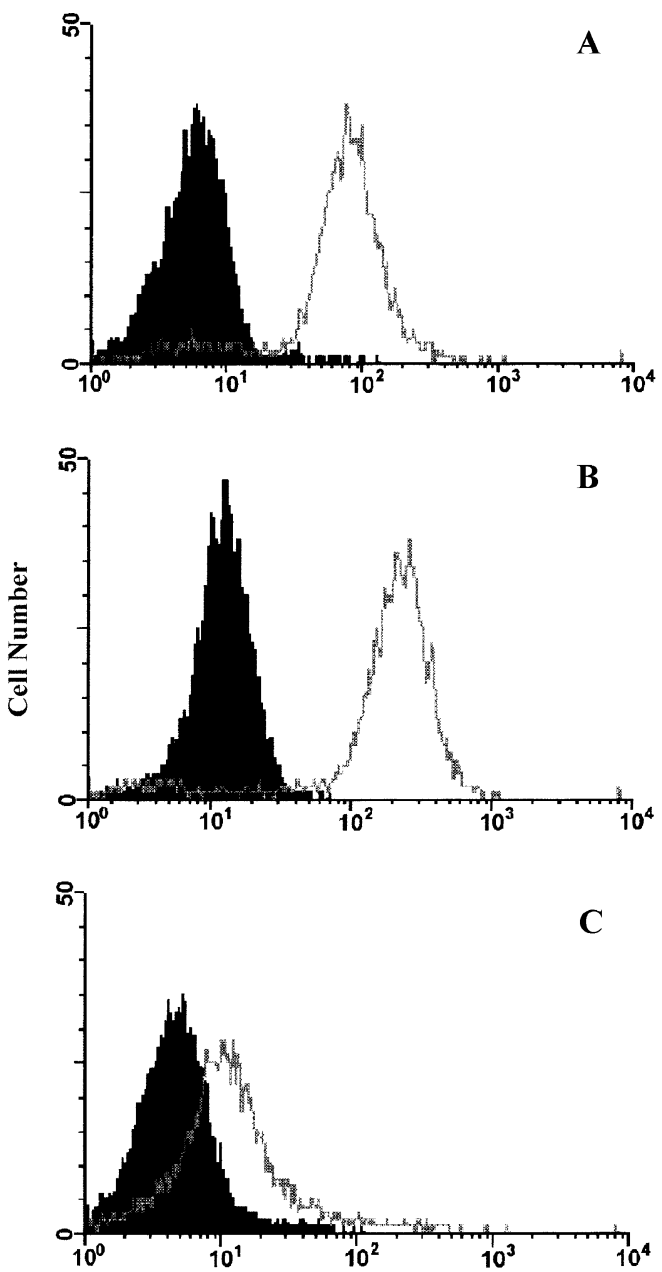

Fas Expression

Figure 1. Fas antigen expression on Jurkat (panel A), Hut78 (panel B), and P815 (panel C) cell lines. Tumor cell lines were stained with FITC coupled anti-Fas monoclonal antibodies as described in Methods. Filled curves represent staining with a FITC labeled isotype control and open curves represent staining with anti-Fas antibody-FITC. 
expressed high levels of Fas antigen whereas murine P815 cells had poor expression of this antigen. Even though Hut78 and Jurkat were human cell lines and P815 was a mouse cell line, it did not matter for our studies since both human and mouse Fas are well recognized by mouse FasL molecule (Alderson et al., 1994; Nagata and Goldstein 1995; Nagata and Suda, 1995).

Lysis of Hut78, Jurkat and P815 target cells by ConA activated spleen cells from young and old mice Hut78, Jurkat and P815 target cell lines were used as targets for assessing the lytic activity of Con-A activated spleen cells from young and old mice. None of these target cell lines was susceptible to lysis by unstimulated mouse spleen cells (Results not shown). Spleen cells from young and old $\mathrm{C} 57 \mathrm{BI} / 6$ mice were activated with Con-A $(5 \mu \mathrm{g} / \mathrm{ml})$ for one or three days and the levels of
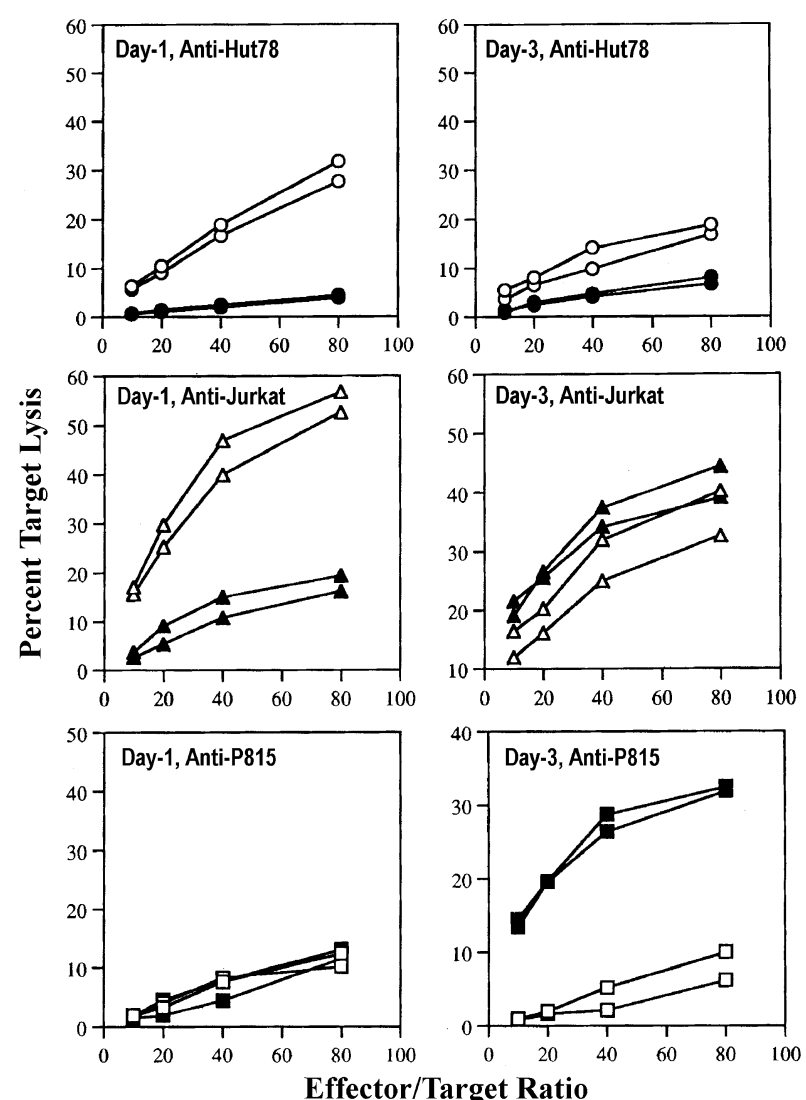

Figure 2. Cytotoxic activity generated in old and young mouse spleen cells activated with Con-A. Spleen cells from young and old mice were activated with Con-A as described in Methods and tested for cytotoxic activity against Hut78, Jurkat and P815 cell line at four E/T ratios, in a four hour chromium release assay of cytotoxicity. Each panel has information about the duration of activation and the target cell used. Results obtained with two young (open symbols) and two old (closed symbols) mouse spleen cell cultures, have been shown in each panel. Similar results (not shown) were obtained in 3 to 6 experiments in each case. Each point on the figure represents mean value for two replicate observations. cytotoxic activity generated against different tumor target cells were assessed. Representative results are given in Figure 2. On day 1, Con-A activated spleen cells from young mice generated high levels of cytotoxic activity against Hut78 and Jurkat cell lines whereas spleen cells from old mice developed little cytotoxic activity against these targets. One day activated spleen cell preparations from both old and young mice, however, failed to induce significant lysis of P815 target cells (Figure 2). After three days of activation with Con-A, spleen cells from old mice generated markedly higher levels of cytotoxicity against P815 target cells, as compared to the cytotoxicity levels generated by the young spleen cells (Figure 2). Anti-Jurkat and anti-Hut78 lytic activities of three days activated old and young mouse spleen cells, however, were comparable (Figure 2).

\section{Effect of anti-Fas antibody on the killing of Hut78 and P815 target cells}

In order to find out if the lytic activity was mediated through Fas antigen, we attempted to block the target lysis by anti-Fas antibody. The effect of anti-Fas antibody on the lysis of Hut78 cells by one day activated young spleen cells at $E / T$ of 80 , is shown in Figure 3 (left panel). These results indicate that anti-Fas antibody may inhibit the lysis of Hut78 cells in a dose dependent manner. Similar results were obtained when E/T ratio of 40 was used (not shown). Lysis of P815 target cells by old mouse spleen cells activated for 3 days with Con-A was not altered in the presence of different concentrations of anti-Fas antibody (Figure 3, right panel). These results suggest that the Fas antigen may be involved in

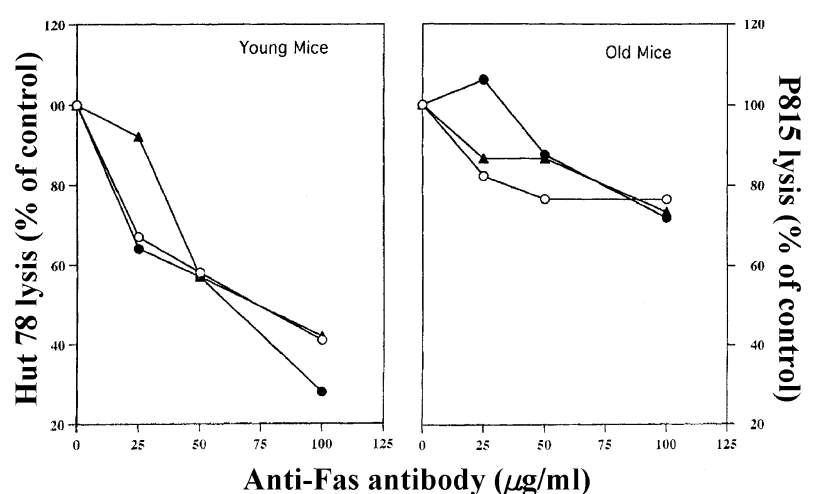

Figure 3. Effect of anti-Fas antibody on the lysis of Hut78 (left panel) and P815 (right panel) by one day activated young and three days activated old spleen effector cells respectively. Chromium labeled target cells $\left(5 \times 10^{3}\right.$ target cells in $0.05 \mathrm{ml} /$ assay well) were incubated with different given concentrations of the anti-Fas monoclonal antibodies for $30 \mathrm{~min}$ at $4^{\circ} \mathrm{C}$. Effector cells $\left(4 \times 10^{5}\right.$ cells in $0.05 \mathrm{ml} /$ assay well) were then added and plates centrifuged (400 rpm $\times 3 \mathrm{~min}$ ) for a four hour chromium release assay of cytotoxicity. Anti-Fas antibodies in absence of effector cells did not have any significant effect on the spontaneous release of Chromium by the two target cells. Target lysis values have been shown as percent of control lysis in absence of anti-Fas antibody, which was taken as 100. Results of three representative experiments have been shown in each panel. 
the killing of Hut78 cells by one day activated young mouse spleen cells, but not in the killing of P815 target cells by three day activated old mouse spleen cells.

\section{Discussion}

We have previously studied and characterized Con-A induced cytotoxic activity in spleen cells derived from young and old mice (Saxena et al., 1981, 1981a). ConA induced cytotoxicity is $T$ cell dependent since no cytotoxic activity could be generated in nude mouse spleen cells or T cell depleted spleen cells (Saxena et al., 1981, 1981a). Cell fractionation studies indicated that the ConA activated cytotoxic effectors did not belong to adherent macrophage or B cell category, and had variable expression of Lyt 2 and asialo GM1 antigens (Saxena et al., 1981). Interestingly, spleen cells from old mice generated significantly higher levels of cytotoxic cells in response to Con-A, as compared to the young (Saxena et al., 1981). In view of the recent thinking about multiple mechanisms of cytotoxicity (Berke 1997; Nagata and Goldstein 1995), we have, in the present study, reexplored the age dependent changes in Con-A induced cytotoxicity in mouse spleen cells.

Though several types of cytotoxic effector lymphocytes can kill tumor targets, it now appears that the mechanism of killing is either through the release of cytotoxic granules or is mediated through a lytic signal provided by interactions between certain specific receptor and ligand molecules (e.g. Fas-FasL) present on target and effector cells (Berke 1997; Nagata and Goldstein 1995). Cross-linkage of Fas molecules expressed on target cells by anti-Fas antibodies or by multivalent FasL molecules on effector cytotoxic cell constitutes a self sufficient death signal for the target cells (Nagata and Suda, 1995; Suda et al., 1993). Mouse and human FasL molecules are $76.9 \%$ homologous and are functionally interchangeable (Nagata and Goldstein, 1995). Human tumor cell lines with high expression of Fas molecules have been used as targets for functional assessment of FasL on murine cytotoxic cells (Alderson et al., 1994; Nagata and Suda, 1995). Fresh mouse spleen cells did not lyse high Fas expressing Hut78 or Jurkat cell lines, suggesting that FasL may not be expressed on fresh non-activated mouse spleen cells. After one day of activation with Con-A, young mouse spleen cells, efficiently lysed Hut78 and Jurkat cell lines (high Fas expressers) but not P815 targets (low Fas expressers). One day activated old mouse spleen cells however did not lyse any of the target cell lines. A tempting explanation of this difference could be that activated young spleen cells lysed Hut78 and Jurkat cell lines through Fas antigen, whereas Fas dependent lytic mechanism was not operative in Con-A activated old mouse spleen cells. This proposition is supported by the observation that anti-Fas antibody could inhibit the lysis of Hut78 cells by one day activated young spleen cells. After three days of activation with Con-A, old mouse spleen cells acquired a high anti-P815 cytotoxic activity, which was not seen with young mouse spleen cells. Since P815 cells have low expression of Fas, their lysis by activated old mouse spleen cells suggests that the mechanism of lysis in this case may not be related to Fas expression. This proposition is also supported by our results which show no effect of anti-Fas antibody on P815 lysis by three day activated old mouse spleen cells.

We have previously shown that Con-A activation of spleen cells derived from old but not young mice, resulted in high levels of cytolytic activity against some target cell lines including P815 cells (Saxena et al., 1988a). These results have been confirmed in the present study. In addition, we find the trend is reversed when high Fas expressing target cells, and a shorter activation period ( 1 day) are used. Taken together our results suggest that in the early phases of activation, effector cells killing through Fas dependent cytolytic mechanism, are preferentially induced in young mouse spleen cells. Cytolytic mechanisms not involving Fas may not get activated in young spleen cells even in late phases of activation, since anti-P815 cytolytic activity remained poor in three day activated young spleen cells. Lack of early activation of Fas dependent cytolytic mechanisms, coupled with a late over-activation of fas unrelated mechanisms of killing may be a characteristic feature of old mouse spleen cells, and may result from age dependent alterations in mechanisms which control the activation of cytotoxic effector cells.

\section{Acknowledgment}

This work was supported by CSIR grant to RKS. Help rendered by Mr. Joe Chrest in obtaining flowcytometric data in Figure 1, is gratefully acknowledged.

\section{References}

Alderson, M. R., Tough, T. W., Braddy, S., Davis-Smith, T., Roux, E., Schooley, K., Miller, R. E. and Lynch, D. H. (1994) Regulation of apoptosis and $\mathrm{T}$ cell activation by Fas-specific mAb. Int. Immunol. 6: 1799-1806

Berke, G. (1997) Killing mechanisms of cytotoxic lymphocytes. Curr. Opin. Hematol. 4: 32-40

Engwerda, C. R., Handwerger, B. S. and Fox, B. S. (1994) Aged T cells are hyporesponsive to costimulation mediated by CD28. J. Immunol. 152: 3740-3747

Ernst, D. N., Wigle, W. O., Noonan, D. N., McQuitty, D. N. and Hobbs, M. V. (1993) The age-associated increase in IFNgamma synthesis by mouse CD8+ $\mathrm{T}$ cells correlates with 
shifts in the frequencies of cell subsets defined by membrane CD44, CD45RB, 3G11, and MEL-14 expression. J. Immunol. 151: $575-587$

Hirano, T. and Nordin, A. A. (1976) Age-associated decline in the in vitro development of cytotoxic lymphocytes in NZB mice J. Immunol. 117: 1093-1098

Lerner, A., Yamada, T. and Miller, R. A. (1989) Pgp-1hi T lymphocytes accumulate with age in mice and respond poorly to concanavalin A. Eur. J. Immunol. 19: 977-982

Mbawuike, I. N., Acuna, C. L., Walz, K. C., Atmar, R. L., Greenberg, S. B. and Couch, R. B. (1997) Cytokines and impaired CD8+ CTL activity among elderly persons and the enhancing effect of IL-12. Mech Ageing Dev. 94: 25-39

Nagata, S. and Goldstein, P. (1995) The Fas death factor. Science 267: 1449-1456

Nagata, S. and Suda, T. (1995) Fas and Fas ligand: Ipr and gld mutations. Immunology Today 16, 39-43

Nagelkerken, L., Hertogh-Huijbregts, A., Dobber, R. and Drager, A. (1991) Age-related changes in lymphokine production related to a decreased number of $\mathrm{CD} 45 \mathrm{RB}^{\mathrm{hi}} \mathrm{CD} 4+\mathrm{T}$ cells. Eur. J. Immunol. 21: 273- 281

Powers, D. C. and Belshe, R. B. (1993) Effect of age on cytotoxic $T$ lymphocyte memory as well as serum and local antibody responses elicited by inactivated influenza virus vaccine J. Infect. Dis. 167, 584-592

Saxena, R. K., Adler, W. H. and Nordin, A. A. (1981) Modu- lation of natural cytotoxicity by alloantibodies. IV. A comparative study of the activation of mouse spleen cell cytotoxicity by anti $\mathrm{H}-2$ antisera, interferon, and mitogens Cellular Immunol. 63: $28-40$

Saxena, R. K., Saxena, Q. B. and Adler, W. H. (1988a) Lectininduced cytotoxic activity in spleen cells from young and old mice. Age-related changes in types of effector cells, lymphokine production and response. Immunology 64: 457-461

Saxena, R. K., Saxena, Q. B. and Adler, W. H. (1988b) Properties and characterization of a rat spleen cell-derived factor that induces resistance to natural killer cell lysis in YAC lymphoma cells. J. Immunol. 141: 1782-1787

Song, L., Kim, Y. H., Chopra, J. J., Proust, J. J., Nagel, J. E., Nordin, A. A. and Adler, W. H. (1993) Age-related effects in T cell activation and proliferation. Exp. Gerontol. 28: 313-321

Suda, T., Takahashi, T., Goldstein, P. and Nagata, S. (1995) Molecular cloning and expression of the Fas ligand, a novel member of the tumor necrosis factor family. Cell 75: 11691178

Tsutsui, H., Nakanishi, K., Matsui, K., Higashino, K., Okamura, H., Miyazawa, Y. and Kaneda, K. (1996) IFN-gamma-inducing factor up-regulates Fas ligand-mediated cytotoxic activity of murine natural killer cell clones. J. Immunol. 157: 3967-73

Wong, G. H. W. and Goeddel, D. V. (1994) Fas antigen and p55 TNF receptor signal apoptosis through distinct pathways. J. Immunol. 152: 1751-1755 